\title{
Application of Dense Offshore Tsunami Observations from Ocean Bottom Pressure Gauges (OBPGs) for Tsunami Research and Early Warnings
}

\author{
5 Mohammad Heidarzadeh and Aditya R. Gusman
}

\begin{abstract}
We introduce a new data source of dense deep-ocean tsunami records from Ocean Bottom Pressure Gauges (OBPGs) which are attached to Ocean Bottom Seismometers (OBS) and apply them for far-field and near-field tsunami warnings. Tsunami observations from OBPGs are new sources of deep-ocean tsunami observations which, for the first time, provide dense tsunami data with spacing intervals in the range of $10-50 \mathrm{~km}$. Such dense data are of importance for tsunami research and warnings and are capable of providing new insights into tsunami characteristics. Here, we present a standard procedure for the processing of the OBPG data and extraction of tsunami signals out of these high-frequency data. Then, the procedure is applied to two tsunamis of 15 July 2009 Mw 7.8 Dusky Sound (offshore New Zealand) and 28 October $2012 \mathrm{Mw} 7.8$ Haida Gwaii (offshore Canada). We successfully extracted 30 and 57 OBPG data for the two aforesaid tsunamis, respectively. Numerical modeling of tsunami was performed for both tsunamis in order to compare the modeling results with observation and to use the modeling results for the calibration of some of the OBPG data. We successfully employed the OBPG data of the 2012 Haida Gwaii tsunami for tsunami forecast by applying a data assimilation technique. Our results, including two case studies, demonstrate the high potential of OBPG data for contribution to tsunami research and warnings. The procedure developed in this study can be readily applied for the extraction of tsunami signals from OBPG data.
\end{abstract}

M. Heidarzadeh ( $\square)$

Department of Civil and Environmental Engineering, Brunel University London,

Uxbridge UB8 3PH, UK

e-mail: mohammad.heidarzadeh@brunel.ac.uk

A. R. Gusman

GNS Science, Lower Hutt, New Zealand

e-mail: a.gusman@gns.cri.nz

T. S. Durrani et al. (eds.), Geological Disaster Monitoring Based on Sensor

Networks, Springer Natural Hazards, https://doi.org/10.1007/978-981-13-0992-2_2 


\section{Introduction and Background}

Tsunami science, in general, is younger than earthquake; mainly because the available observations for tsunamis are less than those for earthquakes. Lack of enough observations has been a main barrier to the development of tsunami science [19]. Tsunami observations are made usually by coastal tide gauges (e.g. [9, 10] and offshore gauges in the form of Deep-ocean Assessment and Reporting of Tsunamis (DART) $[2,3,8]$ as well as offshore cabled tsunami gauges such as the Canadian North-East Pacific Underwater Networked Experiments (NEPTUNE) (Rabinovich and Eble [16]. However, most of the tsunami observations have been from tide gauges until 1990s when DARTs were born. Deep-ocean records of tsunamis are free from coastal effects such as harbor resonance [7], nonlinear effect (e.g. [4], and coastal refractions and scattering [11]. Hence, deep-ocean tsunami observations provide refined information about tsunami characteristics [10]. Observations from DARTs are significantly important for tsunami research and warnings and have provided the opportunity to study ocean-wide propagation of tsunamis and to develop a tsunami warning system in the Pacific Ocean [20]. The total number of DARTs installed in the Pacific, Atlantic and Indian/Oceans is $\sim 60$. Although installation and maintenance of this number of DARTs is a major progress worldwide in tsunami research and has been very costly (installation of each DART approximately costs US\$250k), it is not enough to provide high spatial resolution of trans-Pacific tsunamis. The distances between neighboring DARTs are in the range $400-4000 \mathrm{~km}$. Given a wavelength of upto $\sim 500 \mathrm{~km}$ for tsunami waves in deep-ocean, it is clear that DART records are very sparse to capture a full tsunami wavelength. In fact, the available deep-ocean measurements of tsunamis through DARTs are limited and sparse. Therefore, it is necessary to look for alternate complementary sources of deep-ocean tsunami measurements.

In past few years, Ocean Bottom Pressure Gauges (OBPG) were added to Ocean Bottom Seismometers (OBS); thus OBSs have been able to record tsunami waves in addition to seismic waves. Because OBSs are deployed in a dense array (upto around 100 instruments) with spacing of $10-50 \mathrm{~km}$, the tsunami records by OBPGs have high spatial resolution. Figures 1 shows dense OBSs which have been deployed in past few years in world's oceans. Some of these OBS systems have been equipped with OBPGs which enabled them to record the trans-oceanic tsunamis (Fig. 1). According to Fig. 1, among the recorded tsunami events by OBPGs are the 2009 Dusky Sound (offshore New Zealand), the 2011 Japan and the 2012 Haida Gwaii (offshore Canada) events.

OBPGs are different from DARTs in several ways: (1) OBSs are usually deployed for few-year campaigns and thus are not permanent stations whereas DARTs are permanent, (2) OBSs store the sea-level data in their hard disks which can be accessed usually at the end of the campaigns or at certain intervals while DARTs provide real-time data through satellite connections, (3) the OBS data have 


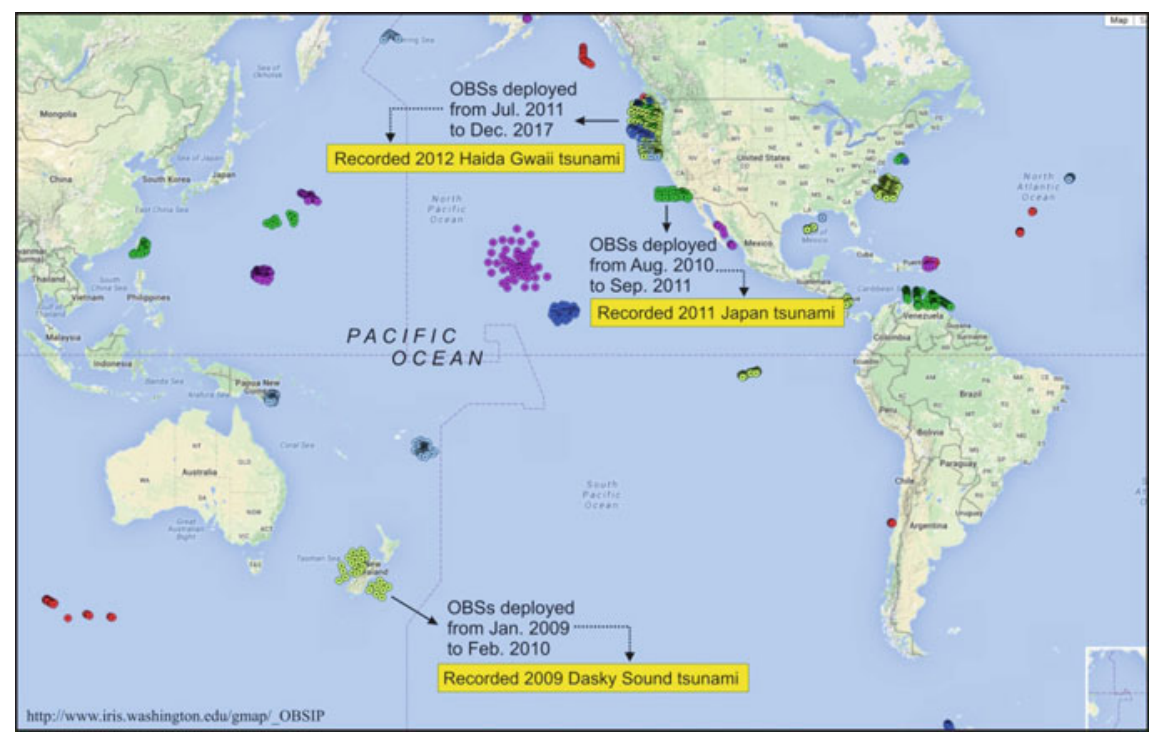

Fig. 1 Locations of OBS campaigns deployed in world's oceans which record both seismic and tsunami waves through OBPGs (original figure from: http://www.iris.washington.edu/gmap/_ OBSIP). The three tsunamis of 2009 Dusky Sound, 2011 Japan and 2012 Haida Gwaii were recorded by the OBS systems through their OBPGs

high sampling rates of 10-50 samples per second while DARTs record the tsunami waves with a rate of 1 record per $15 \mathrm{~s}$ at best, and (4) OBSs are deployed in large numbers (from $\sim 50$ to $\sim 100$ ) with spacing in the range 10-50 km (Fig. 1) whereas DARTs are limited in number (total number of DARTs is $\sim 60$ worldwide) and are spaced from $\sim 400$ to $\sim 4000 \mathrm{~km}$.

Dense OBPG observations are helpful for tsunami research and warnings. While temporal variations of tsunamis are well known by having a large number of time series of tsunamis, little is known about spatial variations of tsunamis because tsunamis have large wavelengths (i.e. hundreds of kilometers) and dense array of tsunamis have not been available so far. Therefore, it has been impossible to provide several measurements of tsunamis per wavelength as they travel across the world's oceans. Data from dense array of OBS pressure gauges provide several measurements per tsunami wavelength; thus can help to study spatial distribution of tsunamis. In addition, dense array of tsunamis provides new opportunities for tsunami warnings by new methods such as warnings based on direct sea-surface measurements (without knowledge about earthquake source), and successive data assimilations (e.g. [15]; Gusman et al. 2016). Application of both of the aforesaid methods has not been possible for tsunami research so far because such methods require dense observations; i.e. several measurements per tsunami wavelength 
which means observations at 5-20 km intervals. Maeda et al. [15] proposed an assimilation method for tsunami warning which was tested using synthetic data. The real tsunami data provided by OBSs for the 2012 Haida Gwaii tsunami was the first real application of data assimilation method as reported by Gusman et al. (2016). In this study, the tsunami data from OBS pressure gauges are introduced and the data acquisition and preparation are described. Here, we present the results of OBPGs data and tsunami simulations for the 2009 Dusky Sound and the 2012 Haida Gwaii tsunamis.

\section{Data and Different Types of OBS Pressure Gauges}

Data from OBSs are available through the website of the project funded by National Science Foundation (NSF) at: <http://www.obsip.org/>. Figure 1 shows location of OBSs deployed in world's oceans in the past decade. The pressure gauges installed on the OBSs are of two types: (1) Absolute seafloor Pressure Gauges (APG), and (2) Differential seafloor Pressure Gauges (DPG) [5]. The APGs are similar to DARTs and give absolute values of pressure above the instrument. DPGs measure the difference between water pressure above the instrument and the oil pressure within the instrument. Hence, the wave amplitudes obtained from DPGs need calibration. Examples of instrument response for the APGs and DPGs at different frequencies are given in Fig. 2. It can be seen that APGs' response is constant at the tsunami period band $(2 \mathrm{~min}<$ period $<100 \mathrm{~min}$ ) (Fig. 2a) while the response decreases with increase of period for DPGs (Fig. 2b). In other words, the tsunami amplitudes recorded by DPGs are relative values and do not represent the real tsunami amplitudes while their periods are correct. Therefore, amplitudes of DPGs need correction.

In the past decade, few tsunamis have been recorded by OBS pressure gauges among which are the 2009 Dusky Sound tsunami (New Zealand) (Fig. 3), the 2011 Japan tsunami (Fig. 4), and the 2012 Haida Gwaii tsunami (Fig. 5). Figure 6 presents examples of DART, APG and DPG records of the 2012 Haida Gwaii tsunami and comparisons with simulated waveforms. As shown in Fig. 6, the amplitudes of the waves recorded by DPGs are larger than those recorded by neighboring DARTs and APGs. This is because of the differential nature of the pressures recorded by the DPG instruments and thus the records need to be corrected. However, the periods of the waves recorded by DPGs are the same as those recorded by APGs and DARTs. Besides the aforesaid three events, other tsunamis also were recorded by the OBS arrays such as the 1 April 2014 Iquique (Chile) tsunami. 
(a) Absolute Pressure Gauge (instrument NZ01 from SIO)

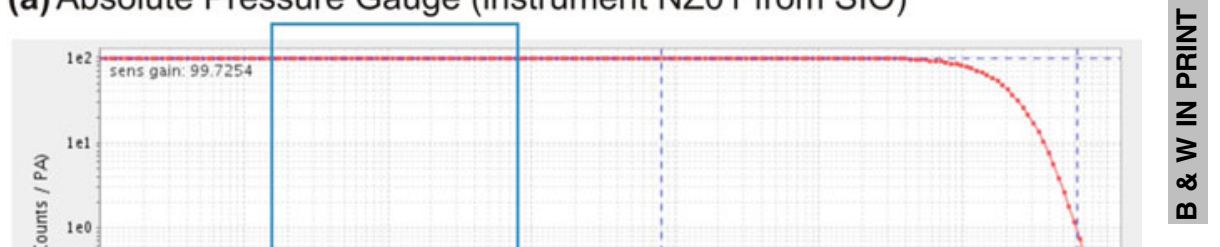

(b) Differential Pressure Gauge (instrument M10B from LDEO)

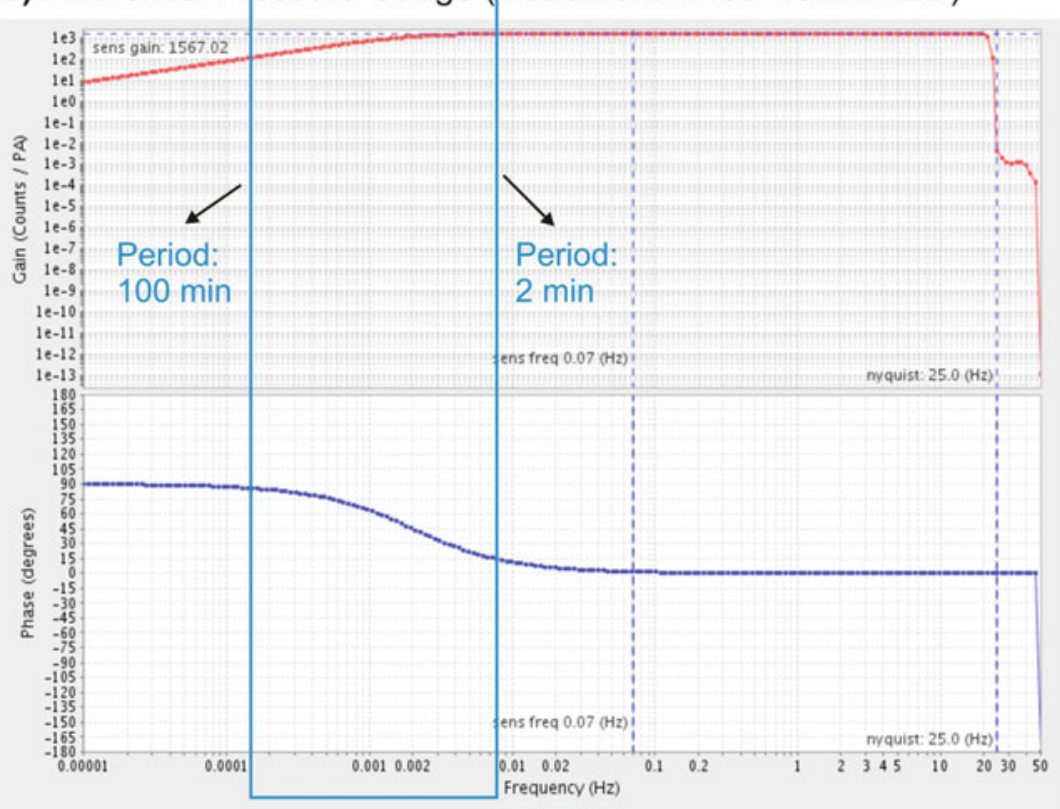

Fig. 2 Sample instrument response for the amplitudes and phases gains at different frequencies for an APG (a) and a DPG instrument (b). SIO and LDEO stand for Scripps Institution of Oceanography and Lamont-Doherty Earth Observatory, respectively. Data from: Incorporated Research Institutions for Seismology Data Management Center (http://ds.iris.edu/mda/_OBSIP) 


\begin{tabular}{|l|lll|}
\hline Layout: T1_Standard & Book ID: 459059_1_En & Book ISBN: 978-981-13-0991-5 \\
Chapter No.: 2 & Date: 6-6-2018 & Time: 6:50 pm & Page: 6/16 \\
\hline
\end{tabular}

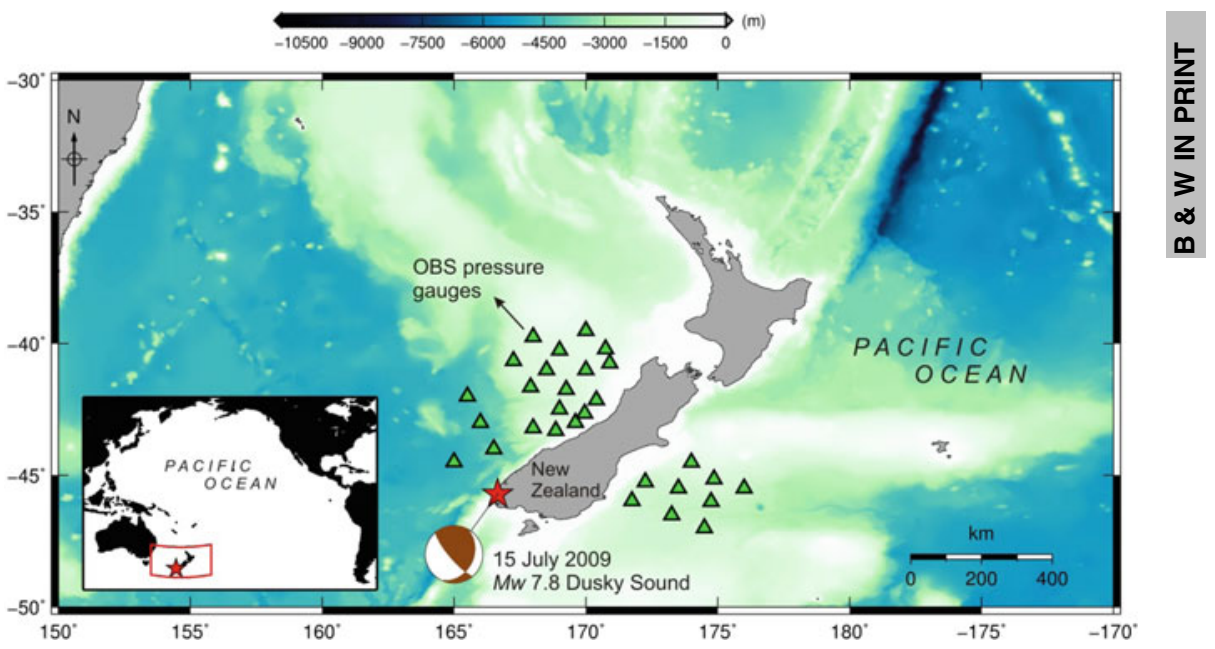

Fig. 3 Locations of OBPG recordings of the 15 July 2009 Dusky Sound tsunami (New Zealand). An array of 30 OBPGs recorded this tsunami

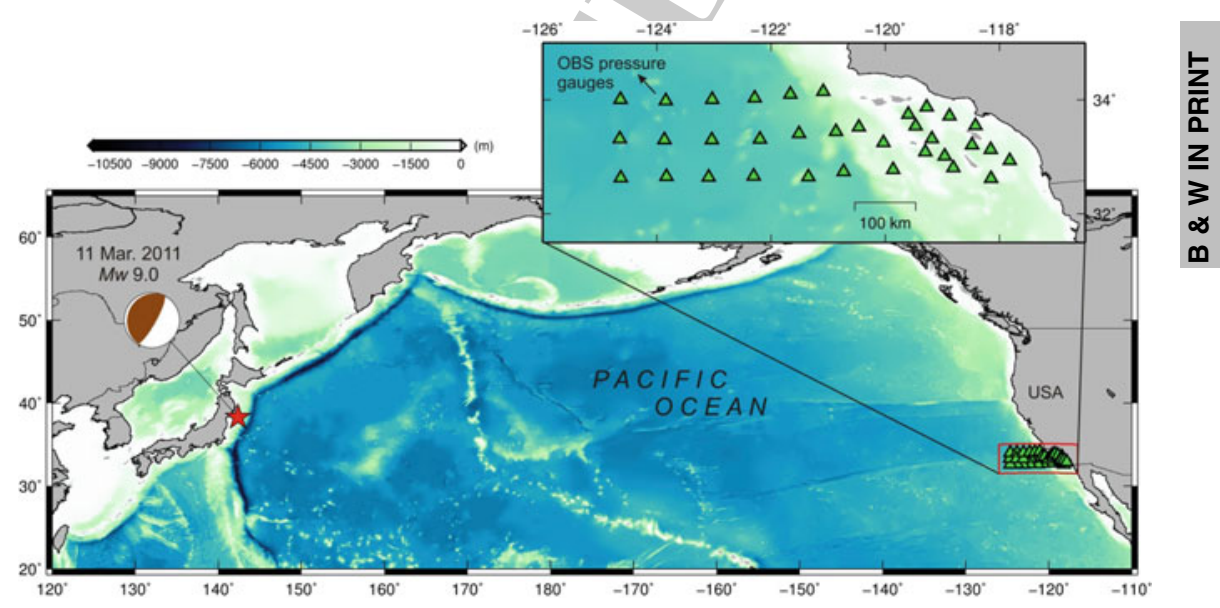

Fig. 4 Locations of OBPG recordings of the 11 March 2011 Japan tsunami. An array of 34 OBPGs recorded this tsunami 


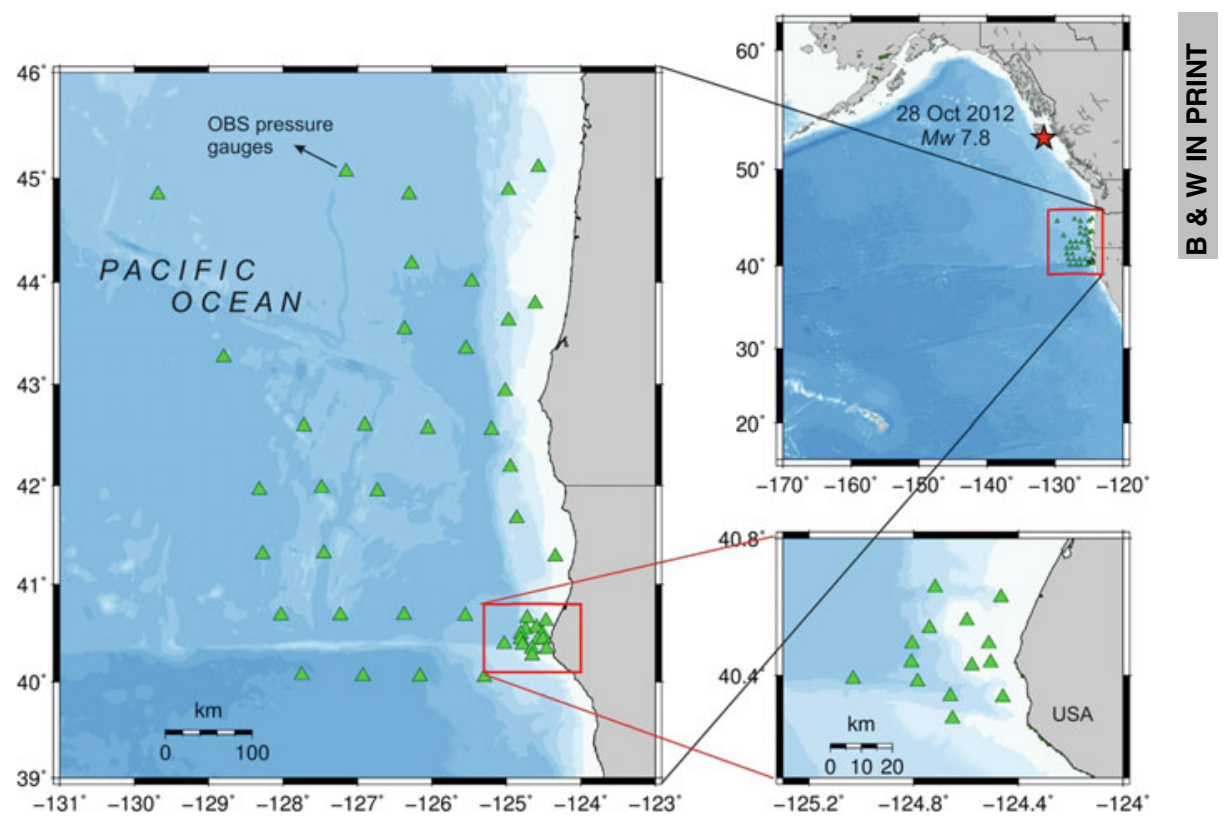

Fig. 5 Locations of OBPG recordings of the 28 November 2012 Haida Gwaii tsunami. An array of 68 OBPGs recorded this tsunami
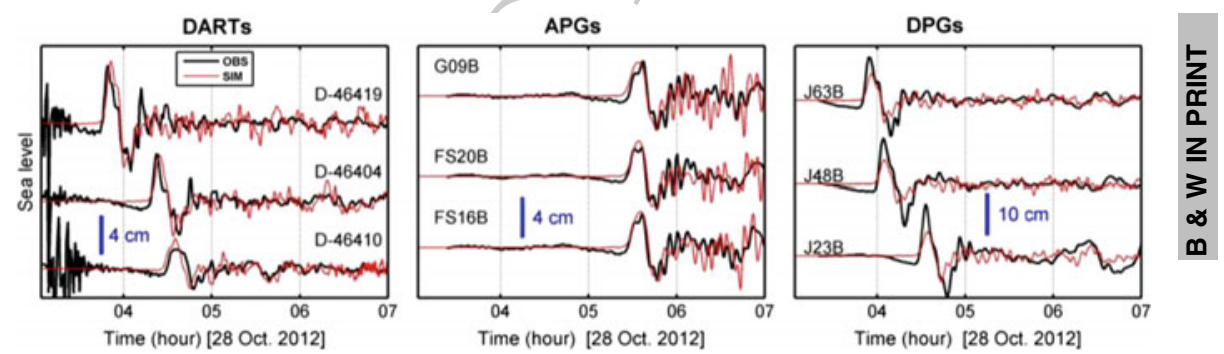

Fig. 6 Examples of DART (left), APG (middle) and DPG (right) records of the 2012 Haida Gwaii tsunami. Black and red waveforms are observed and simulated waveforms, respectively. The observed waveforms from DPGs are noticeably larger than those from DARTs and APGs showing that DPGs need correction (Color figure online)

\section{Methodology}

Unlike Tide Gauge (TG) or DART data, the process of OBPG data is more complicated. Usually, the amplitude values for the TG and DART data are the absolute real-world values. Therefore, a simple high-pass filter will yield the tsunami signal for the TG and DART data. For two types of OBPG data, the APGs give the absolute values of wave amplitude (same as TG and DARTs) while DPGs give 
Table 1 The procedure used for the preparation of tsunami waveforms from the OBPG data

\begin{tabular}{l|l|l}
\hline $\begin{array}{l}\text { Step } \\
\text { number }\end{array}$ & Description of the task & $\begin{array}{l}\text { SAC }^{\text {a }} \\
\text { command }\end{array}$ \\
\hline 1 & Selecting an appropriate length of the data & cut \\
\hline 2 & Removing the mean of the data & rmean \\
\hline 3 & Removing the linear trend & rtrend \\
\hline 4 & Appling a symmetric taper to each end of data & taper \\
\hline 6 & Band pass filtering the data to remove non-tsunami signals & bandpass \\
\hline 7 & Removing the mean of the data & rmean \\
\hline 9 & Removing the linear trend & rtrend \\
\hline 9 & Appling a symmetric taper to each end of data & taper \\
\hline 10 & $\begin{array}{l}\text { Performs deconvolution to remove an instrument response and } \\
\text { convolution to apply another instrument response }\end{array}$ & transfer \\
\hline 11 & Removing the mean of the data & rmean \\
\hline 12 & Removing the linear trend & rtrend \\
\hline
\end{tabular}

${ }^{\mathrm{a} S A C}$ Seismic analysis code

arbitrary numbers which need to be corrected. This correction is conducted using the results of tsunami simulations [5].

To extract the tsunami signals from OBPGs, we first resample the high-frequency date (frequency of 40 or $50 \mathrm{~Hz}$ ) to a low-frequency data (frequency of $0.0167 \mathrm{~Hz}$ ), then we band-pass filter the original records; finally the instrument responses are de-convolved. For the APGs, we do not correct the amplitude values while the DPG amplitudes need to be corrected using the results of numerical simulations of tsunamis. The software package SAC (Seismic Analysis Code) (https://ds.iris.edu/ files/sac-manual/) is used for processing the OBPG data. Table 1 provides a summary of the procedure taken for the preparation of the tsunami waveforms from the OBPG data along with relevant SAC commands. Numerical simulations of tsunami waves are conducted using the numerical package of Satake [17] which solves Shallow-Water equations in a spherical domain using the Finite-Difference Method. The 30 arc-sec bathymetry data provided by GEBCO is used here for numerical modeling of tsunami [21]. The tsunami source models used for the simulations of the events are based on the model by Gusman et al. [6] for the 2012 Haida Gwaii event (Mw 7.8) and that of Beavan et al. [1] for the 2009 Dusky Sound event (Mw 7.8).

\section{Case Study One: The 2012 Haida Gwaii Tsunami, Offshore Canada}

On 28 October 2012, 03:04:09 UTC, an earthquake with Mw 7.8, which is known as the 2012 Haida Gwaii earthquake, occurred offshore British Columbia, Canada. The earthquake was initiated at $52.622^{\circ} \mathrm{N}, 132.103^{\circ} \mathrm{W}$, at the depth of $14 \mathrm{~km}$ [13], 


\begin{tabular}{|l|lll|}
\hline Layout: T1_Standard & Book ID: 459059_1_En & Book ISBN: 978-981-13-0991-5 \\
Chapter No.: 2 & Date: 6-6-2018 & Time: 6:50 pm & Page: 9/16 \\
\hline
\end{tabular}

Application of Dense Offshore Tsunami Observations from Ocean ...
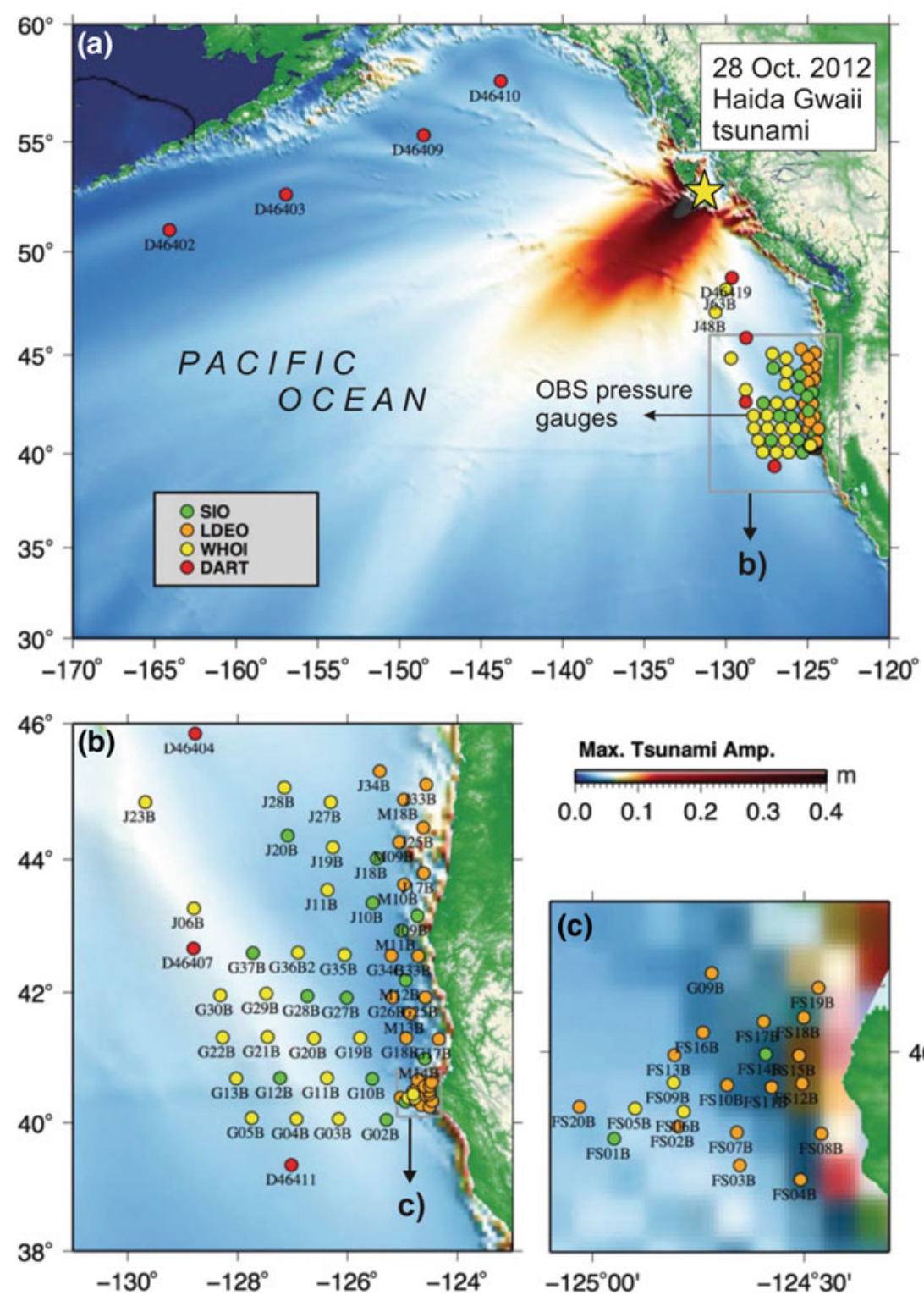

Max. Tsunami Amp.
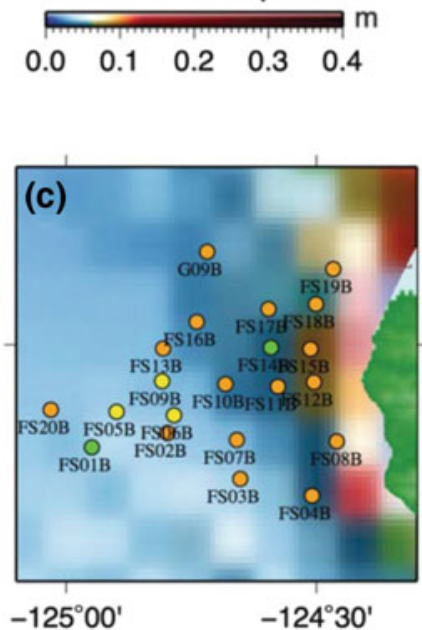

$40^{\circ} 30^{\prime}$

Fig. 7 The maximum simulated tsunami amplitudes due to the 28 November 2012 Haida Gwaii tsunami and locations of DARTs and OBSs. The OBSs are shown by green (Scripps Institution of Oceanography, SIO), brown (Lamont Doherty Earth Observatory, LDEO) and yellow (Woods Hole Oceanographic Institution, WHOI) circles. Modified from Sheehan et al. [18]. An array of more than 50 OBSs recorded this tsunami (Color figure online) 
and ruptured all the way upto the trench axis with a thrust fault motion. A strong tsunami was generated by the earthquake with maximum run-up of $13 \mathrm{~m}$ being observed in the near field [14]. The tsunami was recorded on DART stations as well as on the dense array of OBPGs in the Cascadia subduction zone located about $1000 \mathrm{~km}$ from the earthquake source region. A total of 57 tsunami waveforms were observed at 8 DARTs, 19 APGs provided by Lamont Doherty Earth Observatory (LDEO), 9 DPGs provided by Scripps Institution of Oceanography (SIO), and 21 DPGs provided by Woods Hole Oceanographic Institution (WHOI) [5, 18] (Fig. 7). The waveforms are presented in Sheehan et al. [18] and Gusman et al. (2016). Figure 8 compares the spectra of the recorded and simulated waveforms from the 2012 Haida Gwaii tsunami. It can be seen that the spectral content of all recorded data, including DPGs, are very similar to those of simulations.

The tsunami waveforms were used to demonstrate the progressive data assimilation method [15] to produce wave fields in the vicinity of the array, then forecasting of wave fields by numerical forward modeling [5]. The tsunami wave field is corrected by using the observed tsunami amplitudes at every time step of $1 \mathrm{~s}$. To transmit the information of tsunami amplitude from each station to its surrounding area, a linear interpolation method [12] is used.

The tsunami reached the northern most station in the modeling domain of the Cascadia subduction zone approximately $70 \mathrm{~min}$ after the earthquake. This can be considered as the effective start time for the tsunami data assimilation process. At the beginning of the process an accurate tsunami wave field could not be obtained because there is no information about the tsunami source in tsunami data assimilation method. Accurate wave field prediction can only be achieved after the tsunami passes through several observation stations. For the case of the Haida Gwaii tsunami with the station configuration, the general pattern of a realistic tsunami wave in the Cascadia subduction zones begins to emerge at $30 \mathrm{~min}$ after the tsunami data assimilation process or after the tsunami passes through 5 stations. The performance of the forecast algorithm using tsunami data assimilation method is evaluated by comparing the forecasted waveforms with the observations. Figure 9 shows the forecast accuracy versus the length of data used for assimilation. High accuracies of more than $80 \%$ of forecasted tsunami waveforms produced from the $60 \mathrm{~min}$ (130 min after the earthquake) data-assimilated wave field are obtained at stations in the southern part of the modeling area.

\section{Case Study Two: The 2009 Dusky Sound Tsunami, Offshore New Zealand}

An earthquake with moment magnitude (Mw) of 7.8 occurred in Dusky Sound, New Zealand on 15 July 2009 (see Fig. 10 for epicenter). According to the United States Geological Survey (USGS), the earthquake origin time was 09:22:33 UTC on 15 July 2009 , located at $45.722^{\circ} \mathrm{S} 166.64^{\circ} \mathrm{E}$ and at the depth of $35 \mathrm{~km}$ (Fig. 10). 


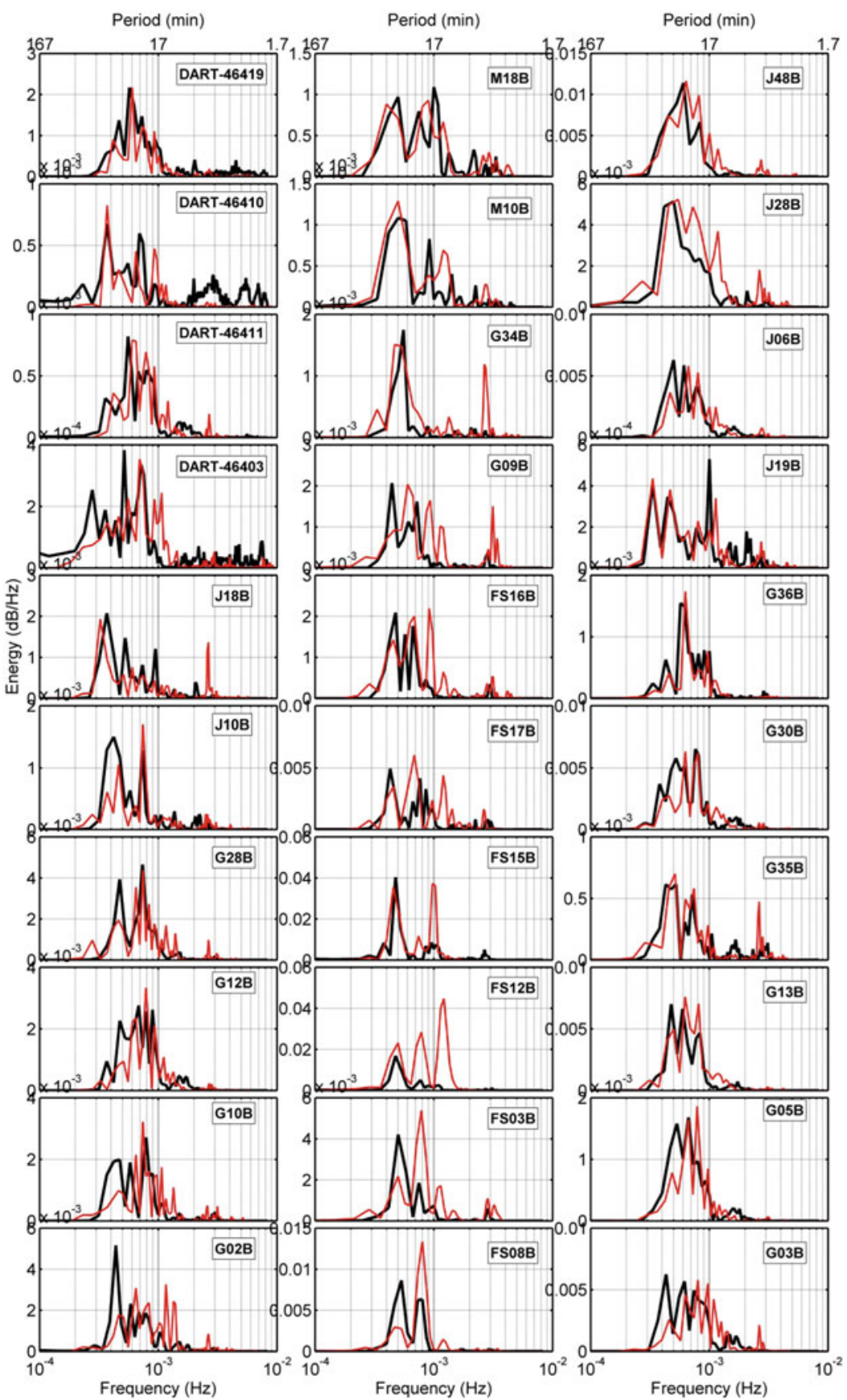

Fig. 8 Comparison of the spectra of the recorded and simulated waveforms from the 2012 Haida Gwaii tsunami 

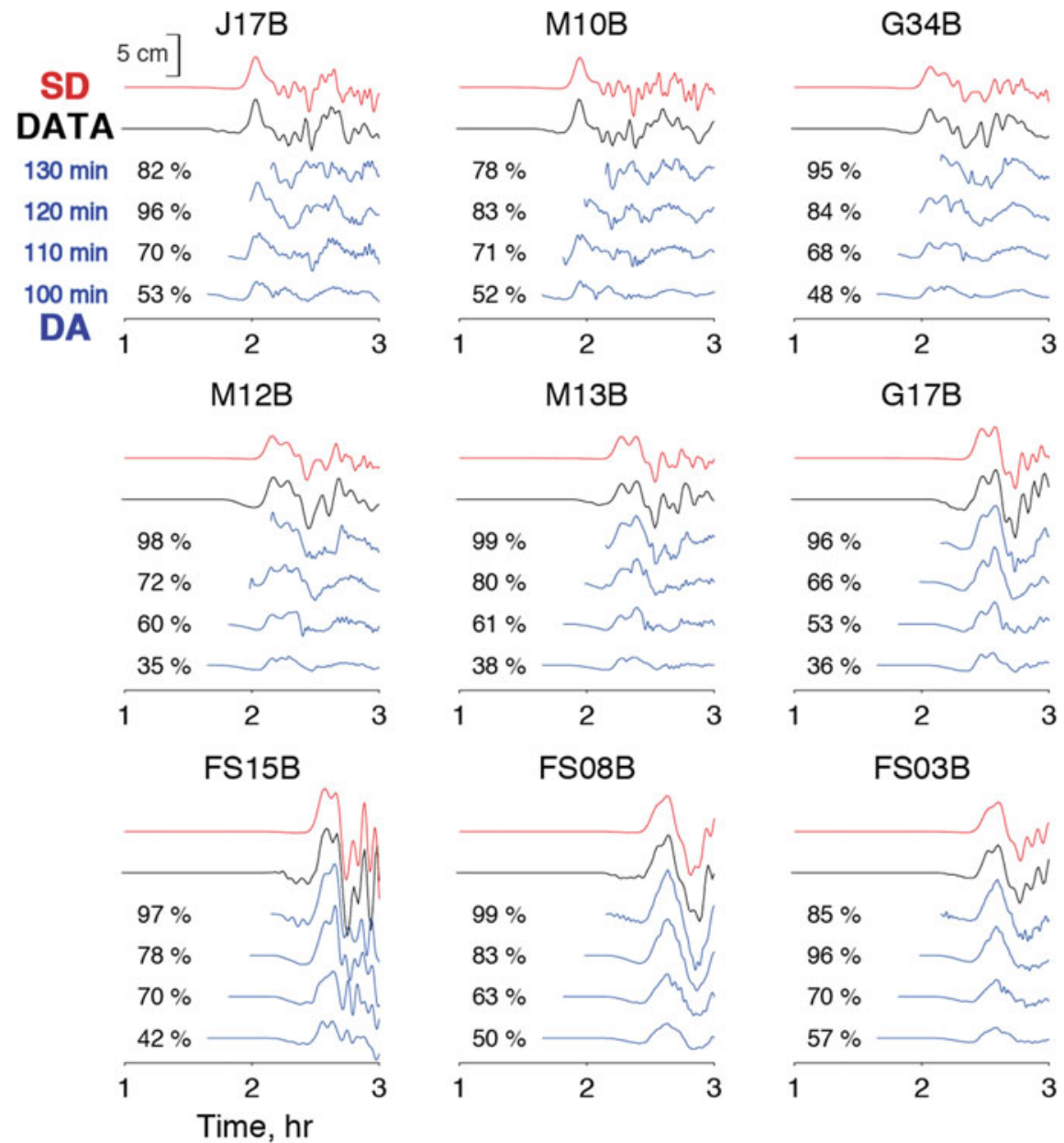

FS03B

Fig. 9 Comparison of tsunami data from simulations using slip model (SD) (red), observations (black), and simulations from the data assimilation technique (DA) wave fields (blue). The numbers 100, 110, 120, and $130 \mathrm{~min}$ are the length of data used for data assimilations. These OBPG stations show here are located at distances $<100 \mathrm{~km}$ from the coast. The performance of data assimilation technique in reproducing the observations is shown as percentage [5] (Color figure online)

This earthquake was the largest earthquake in New Zealand since 1931 (Beavan et al. 2009). The earthquake triggered a tsunami which was recorded on a number of tide gauges and Deep-Ocean Assessment and Reporting of Tsunami (DART) gauges (see Fig. 10 for locations of the gauges and Fig. 11 for the waveforms). At the time of the 2009 earthquake and tsunami, a campaign of OBSs was in operation 


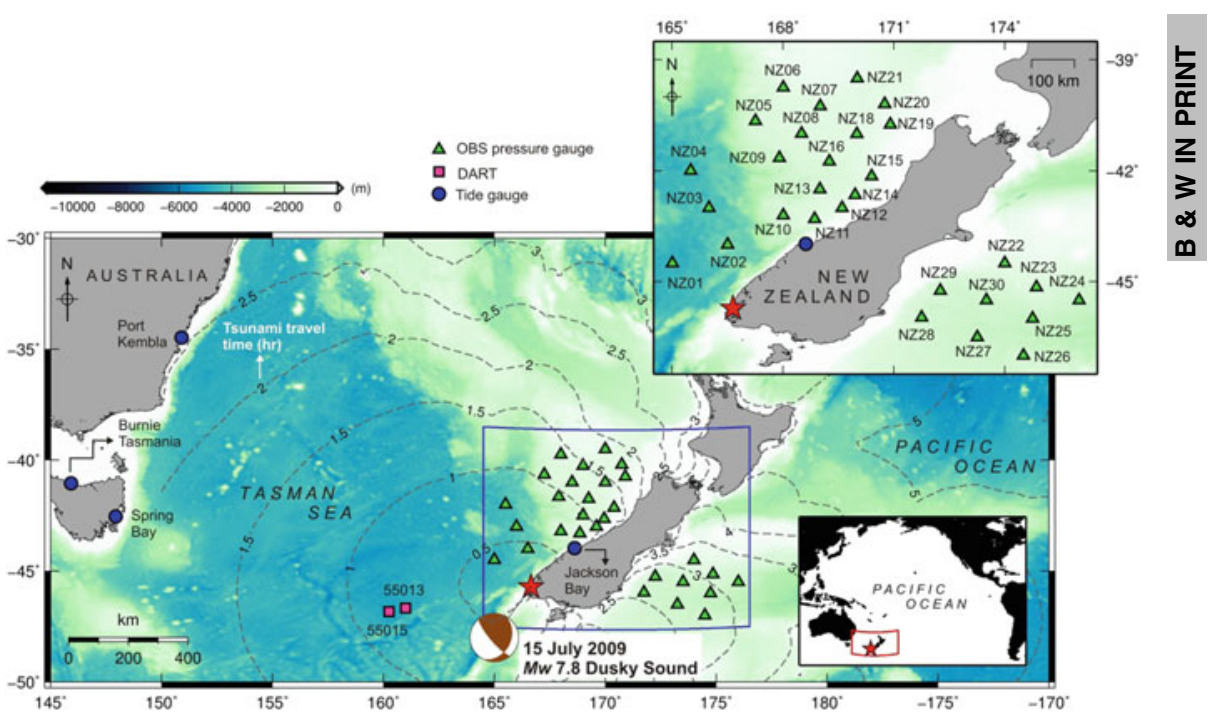

Fig. 10 Epicentral area and location of various sea level gauges used in this study including OBPGs, TGs and DARTs. The red start shows the earthquake epicenter. Dashed contours are tsunami travel times in hours (Color figure online)

in the same region (Fig. 10). These OBSs also recorded the tsunami as they were equipped with OBPGs. All of the OBPGs are of the DPG type which means the pressure values are not the absolute values. Therefore, the amplitude values were corrected using the results of tsunami simulations (Fig. 11).

While tsunami signals were fully hidden in high-frequency recordings of the OBPGs, we were able to successfully extract the tsunami signals by applying re-sampling, filtering, and de-convolving the DPG instrument response (the procedure presented in Table 1). In our processed OBPG tsunami data (black lines in Fig. 11), the tsunami arrival times were clear and the signals had periods in the range of 10-20 min which is the expected period range for a tsunami generated by a Mw 7.8 earthquake. Numerical modeling of tsunami was conducted by using the tsunami source proposed by Beavan et al. [1] (Fig. 11a). Simulations were able to fairly reproduce the observations from OBPG, DART and tide gauge stations. However, the amplitudes of the OBPG-DPG data were larger than the simulations; therefore, we corrected the OBPG-DPG amplitudes by applying arbitrary ratios in order to match them with the maximum amplitudes from tsunami simulations for each instrument. Based on Fig. 11, the match for DART and tide gauge records was better than that for OBPGs. 


\begin{tabular}{|l|lll|}
\hline Layout: T1_Standard & Book ID: 459059_1_En & Book ISBN: 978-981-13-0991-5 \\
Chapter No.: 2 & Date: 6-6-2018 & Time: 6:50 pm & Page: 14/16 \\
\hline
\end{tabular}

(a): The slip model and crustal deformation
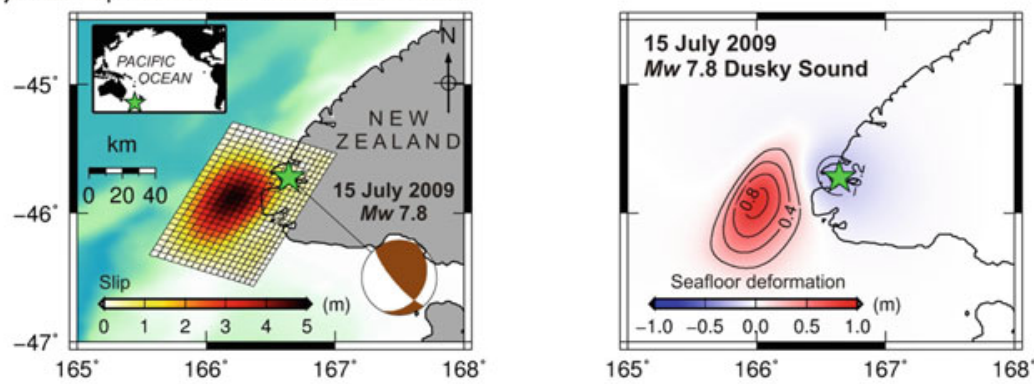

(b): Waveforms
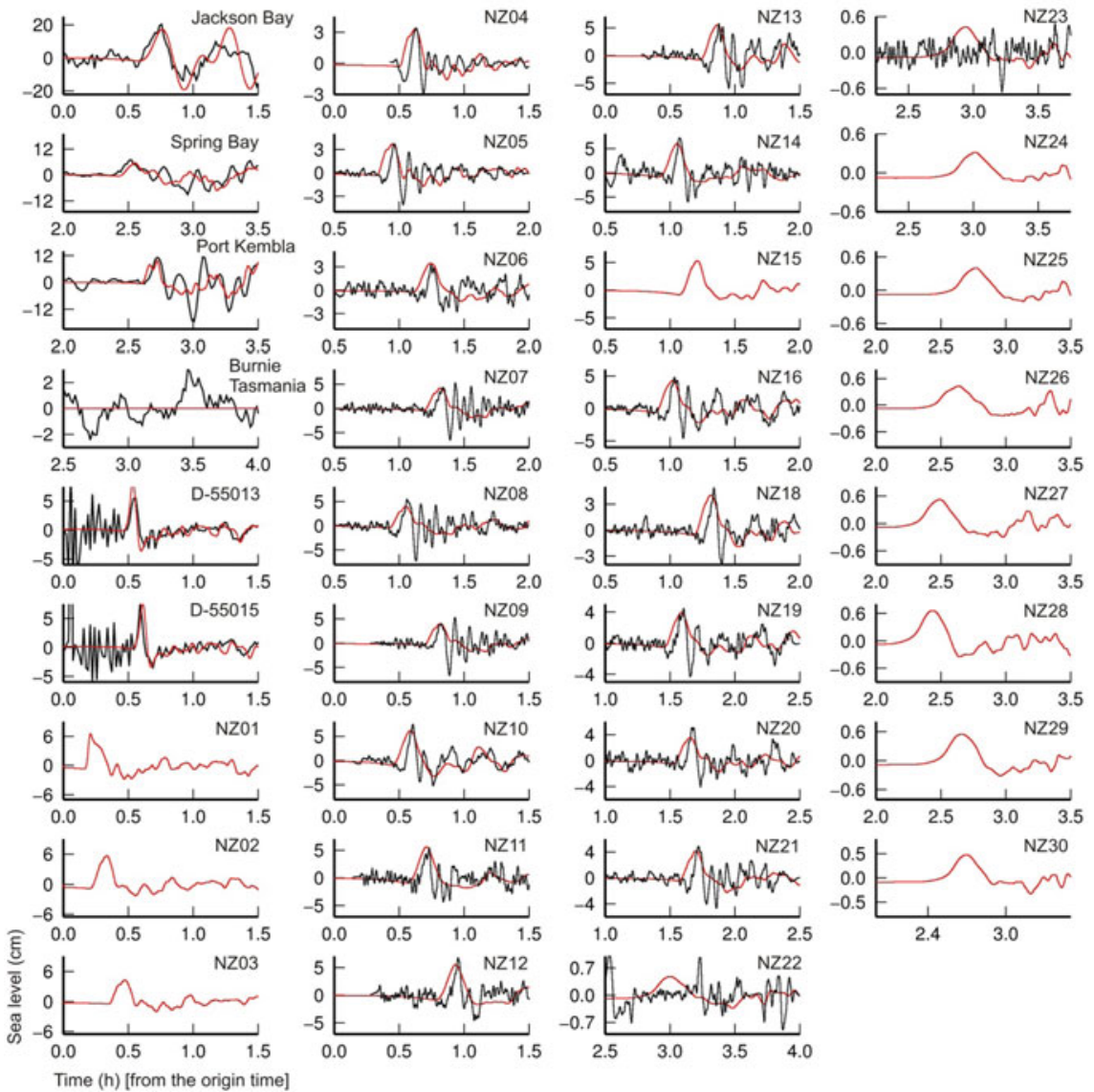

Fig. 11 a Source model of the 2009 earthquake according to the model published by Beavan et al. [1]. b Comparison of observed (black) and simulated (red) tsunami waveforms for the 2009 Dusky Sound tsunami. The locations of the gauges are shown in Fig. 10. For OBS gauges NZ-15, and from NZ-24 to NZ-30, the tsunami signals are not clear and are hidden within the noise level (Color figure online) 


\section{Conclusions}

We introduced a new source of dense offshore tsunami observations from Ocean Bottom Pressure Gauges (OBPGs) which are attached to Ocean Bottom Seismometers (OBSs). Until recently (i.e. around 2015), offshore deep-ocean tsunami observations were made through DARTs (Deep-ocean Assessment and Reporting of Tsunamis). However, OBPG observations have two main advantages over DARTs namely: (1) they come with large numbers (upto 100) and dense distribution with spacing of $10-50 \mathrm{~km}$ versus $200-4000 \mathrm{~km}$ of DARTs, and (2) they have high frequency with sampling rates of $40-100 \mathrm{~Hz}$ versus that of $0.016 \mathrm{~Hz}$ for DARTs. The data processing and preparations are more complicated for OBPGs than DARTs. We presented a standard procedure and the sequence of tasks that needs to be taken for the processing of the OBPG data and extraction of the tsunami signals. The procedure is then applied to the two tsunamis of 2009 Dusky Sound (offshore New Zealand) and the 2012 Haida Gwaii (offshore Canada). Our results showed that the standard procedure used for the extraction of the OBPG data was successful in revealing tsunami signals in both cases. The OBPG instruments for these two events were either Differential seafloor Pressure Gauges (DPGs) or Absolute seafloor Pressure Gauges (APGs). The amplitudes from APGs are real values while those from DPGs are relative values and need correction. For the cases of the DPG data, we corrected the amplitudes of the observations signals using the results of tsunami simulations. The OBPG data for the 2012 Haida Gwaii event were successfully applied for tsunami forecast using the data assimilation technique.

Acknowledgements We acknowledge NOAA (National Oceanic and Atmospheric Administration of the US) for providing the DART data (http://www.ndbc.noaa.gov/dart.shtml), the IOC (Intergovernmental Oceanographic Commission) for the tide gauge records (http://www. ioc-sealevelmonitoring.org/) and the Incorporated Research Institutions for Seismology Data Management Center for the OBPG records (http://ds.iris.edu/mda/_OBSIP). Authors would like to thank Kenji Satake (The University of Tokyo, Japan), Tomohiro Takagawa (Port and Airport Research Institute, Japan), Shingo Watada (The University of Tokyo, Japan) and Anne Sheehan (University of Colorado, US) for their collaboration on the analysis of the OPBG records. Parts of this study were previously presented at the AGU (American Geophysical Union) fall meeting in San Francisco (US) in December 2016. The lead author (MH) was funded by the Brunel University London through the Brunel Research Initiative and Enterprise Fund 2017/18 (BUL BRIEF).

\section{References}

1. Beavan J, Samsonov S, Denys P, Sutherland R, Palmer N, Denham M (2010) Oblique slip on the Puysegur subduction interface in the 2009 July MW 7.8 Dusky Sound earthquake from GPS and InSAR observations: implications for the tectonics of southwestern New Zealand. Geophys J Int 183(3):1265-1286

2. Geist EL, Titov VV, Synolakis CE (2006) Tsunami: wave of change. Sci Am 294(1):56-63 
3. Gonzalez FI, Milburn HM, Bernard EN, Newman JC (1998) Deep-ocean assessment and reporting of tsunamis (DART®): brief overview and status report. In: Proceedings of the international workshop on tsunami disaster mitigation, Tokyo, Japan, 19-22 January 1998

4. Gusman AR, Murotani S, Satake K, Heidarzadeh M, Gunawan E, Watada S, Schurr B (2015) Fault slip distribution of the 2014 Iquique, Chile, earthquake estimated from ocean-wide tsunami waveforms and GPS data. Geophys Res Lett 42:1053-1060

5. Gusman AR, Sheehan A, Satake K, Heidarzadeh M, Mulia IE, Maeda E (2016) Tsunami data assimilation of Cascadia seafloor pressure gauge records from the 2012 Haida Gwaii earthquake. Geophys Res Lett 43(9):4189-4196

6. Gusman A, Mulia IE, Satake K, Watada S, Heidarzadeh M, Sheehan AF (2016) Estimate of tsunami source using optimized unit sources and including dispersion effects during tsunami propagation: the 2012 Haida Gwaii earthquake. Geophys Res Lett 43(18):9819-9828

7. Heidarzadeh M, Satake K (2013) The 21 May 2003 Tsunami in the Western Mediterranean sea: statistical and wavelet analyses. Pure Appl Geophys 170(9):1449-1462

8. Heidarzadeh M, Satake K (2013) Waveform and spectral analyses of the 2011 Japan tsunami records on tide gauge and DART stations across the Pacific Ocean. Pure Appl Geophys 170 (6): $1275-1293$

9. Heidarzadeh M, Satake K (2014) Excitation of basin-wide modes of the Pacific Ocean following the March 2011 Tohoku Tsunami. Pure Appl Geophys 171(12):3405-3419

10. Heidarzadeh M, Satake K, Murotani S, Gusman AR, Watada S (2015) Deep-water characteristics of the Trans-Pacific Tsunami from the 1 April $2014 \mathrm{M}$ w 8.2 Iquique, Chile Earthquake. Pure Appl Geophys 172(3-4):719-730

11. Heidarzadeh M, Harada T, Satake K, Ishibe T, Gusman A (2016) Comparative study of two tsunamigenic earthquakes in the Solomon Islands: 2015 Mw 7.0 normal-fault and 2013 Santa Cruz Mw 8.0 megathrust earthquakes. Geophys Res Lett 43(9):4340-4349

12. Kalnay E (2003) Atmospheric modeling, data assimilation, and predictability. Cambridge University Press, Cambridge, UK

13. Kao H, Shan SJ, Farahbod AM (2015) Source characteristics of the 2012 Haida Gwaii earthquake sequence. Bull Seismol Soc Am 105(2B):1206-1218

14. Leonard LJ, Bednarski JM (2014) Field survey following the 28 October 2012 Haida Gwaii tsunami. Pure Appl Geophys 171(12):3467-3482

15. Maeda T, Obara K, Shinohara M, Kanazawa T, Uehira K (2015) Successive estimation of a tsunami wavefield without earthquake source data: a data assimilation approach toward real-time tsunami forecasting. Geophys Res Lett 42(19):7923-7932

16. Rabinovich AB, Eblé MC (2015) Deep-ocean measurements of tsunami waves. Pure Appl Geophys 172:3281-3312

17. Satake K (1995) Linear and nonlinear computations of the 1992 Nicaragua earthquake tsunami. Pure Appl Geophys 144:455-470

18. Sheehan AF, Gusman AR, Heidarzadeh M, Satake K (2015) Array observations of the 2012 Haida Gwaii tsunami using Cascadia Initiative absolute and differential seafloor pressure gauges. Seismol Res Lett 86(5):1278-1286

19. Synolakis CE, Bernard EN (2006) Tsunami science before and beyond Boxing Day 2004. Philos Trans R Soc Lond A 364(1845):2231-2265

20. Titov VV, Gonzalez FI, Bernard EN, Eble MC, Mofjeld HO, Newman JC, Venturato AJ (2005) Real-time tsunami forecasting: challenges and solutions. In: Developing tsunami-resilient communities. Springer, Netherlands, pp 41-58

21. Weatherall P, Marks KM, Jakobsson M, Schmitt T, Tani S, Arndt JE, Rovere M, Chayes D, Ferrini V, Wigley R (2015) A new digital bathymetric model of the world's oceans. Earth Space Sci 2:331-345 


\section{Author Query Form}

\section{Book ID：459059_1_En}

Chapter No : $\mathbf{2}$

\section{算 Springer}

the language of science

Please ensure you fill out your response to the queries raised below and return this form along with your corrections.

Dear Author,

During the process of typesetting your chapter, the following queries have arisen. Please check your typeset proof carefully against the queries listed below and mark the necessary changes either directly on the proof/online grid or in the 'Author's response' area provided below

\begin{tabular}{|l|l|l|}
\hline Query Refs. & Details Required & Author's Response \\
\hline AQ1 & As chapter-wise Keywords are mandatory, please provide the keywords. & \\
AQ2 & $\begin{array}{l}\text { References 'Gusman et al. (2016), Beavan et al. (2009)' are cited in the text } \\
\text { but not provided in the reference list. Please provide the respective } \\
\text { references in the list or delete these citations. }\end{array}$ & \\
\hline
\end{tabular}

